\title{
Development of a Rotating Rake Array for Boundary-Layer- Ingesting Fan-Stage Measurements
}

\author{
John D. Wolter ${ }^{1}$, David J. Arend ${ }^{2}$, and Stefanie M. Hirt ${ }^{3}$ \\ NASA Glenn Research Center, Cleveland, Ohio, 44135 \\ and \\ John A. Gazzaniga ${ }^{4}$ \\ Zin Technologies, Inc., Middleburg Heights, Ohio, 44130
}

\begin{abstract}
The recent Boundary-Layer-Ingesting Inlet/Distortion Tolerant Fan wind tunnel experiment at NASA Glenn Research Center's 8-foot by 6-foot supersonic wind tunnel examined the performance of a novel inlet and fan stage that was designed to ingest the vehicle boundary layer in order to take advantage of a predicted overall propulsive efficiency benefit. A key piece of the experiment's instrumentation was a pair of rotating rake arrays located upstream and downstream of the fan stage. This paper examines the development of these rake arrays. Pre-test numerical solutions were sampled to determine placement and spacing for rake pressure and temperature probes. The effects of probe spacing and survey density on the repeatability of survey measurements was examined. These data were then used to estimate measurement uncertainty for the adiabatic efficiency.
\end{abstract}

\section{Nomenclature}

$\begin{array}{ll}\mathrm{A} & =\text { area } \\ \mathrm{f}_{\mathrm{S}} & =\text { stretch factor } \\ \mathrm{P}_{\mathrm{T}} & =\text { total pressure, psia } \\ \mathrm{P}_{\mathrm{S}} & =\text { static pressure, psia } \\ \mathrm{M} & =\text { Mach number } \\ \mathrm{m} & =\text { number of rakes in the array } \\ \dot{m} & =\text { mass flow, lbm/sec } \\ \mathrm{n} & =\text { number of probes in the rake } \\ \mathrm{Q} & =\text { generic pressure or temperature } \\ \mathrm{r} & =\text { radius } \\ \mathrm{r}_{\mathrm{hub}} & =\text { radius at inner (hub) wall } \\ \mathrm{r}_{\mathrm{casing}} & =\text { radius at outer (casing) wall } \\ \mathrm{R} & =\text { gas constant for air, }=1716.6 \mathrm{ft} \mathrm{lbf}_{\mathrm{slug}} \mathrm{sl}^{-1} \mathrm{R}^{-1} \\ \mathrm{SP}_{\mathrm{P}} & =\text { stage pressure ratio, }=P_{T, F E R R A} / P_{T, A I P R R A} \\ \mathrm{~S}_{\mathrm{T}} & =\text { stage temperature ratio, }=T_{T, F E R R A} / T_{T, A I P R R A} \\ \mathrm{~T}_{\mathrm{T}} & =\text { total temperature, } \mathrm{R} \\ \mathrm{U} & =\text { uncertainty } \\ \eta_{\mathrm{A}} & =\text { adiabatic efficiency } \\ \gamma & =\text { ratio of specific heats, }=1.4\end{array}$

\footnotetext{
${ }^{1}$ Aerospace Engineer, Inlets and Nozzles Branch, 21000 Brookpark Rd., M/S 5-12, Associate Fellow.

${ }^{2}$ Aerospace Engineer, Inlets and Nozzles Branch, 21000 Brookpark Rd., M/S 5-12, Associate Fellow.

${ }^{3}$ Aerospace Engineer, Inlets and Nozzles Branch, 21000 Brookpark Rd., M/S 5-12, Senior Member.

${ }^{4}$ Aerospace Engineer, Acoustics Branch, 21000 Brookpark Rd., M/S 54-3, Senior Member
}

American Institute of Aeronautics and Astronautics 


\section{Introduction}

A multi-disciplinary team from NASA's Glenn Research Center, United Technology Research Center (UTRC), Virginia Tech University, and the Arnold Engineering Development Complex have designed, built and recently tested a new propulsor to demonstrate the benefits of boundary layer ingestion. The Boundary-Layer-Ingesting Inlet/Distortion Tolerant Fan (BLI ${ }^{2} \mathrm{DTF}$ ) experiment was conducted in the 8-foot by 6-foot Supersonic Wind Tunnel at the NASA Glenn Research Center in November and December of 2016.

The propulsor in this experiment comprised a short non-axisymmetric inlet closely coupled to a single-stage lowpressure-ratio fan, and a plug-type nozzle for flow control. This experimental hardware was mounted to a compressedair-powered drive rig. This propulsor was embedded in a raised floor with flow effectors and a bleed system to control the thickness of the boundary layer. Figure 1 shows the BLI ${ }^{2} \mathrm{DTF}$ experimental setup in the $8 \times 6$ wind tunnel. Figure 2 shows a cross-sectional view of the BLI'DTF propulsor.

Previous studies ${ }^{1,2,3,4}$ have shown that boundary layer ingestion offers a potential 3-5\% fuel burn reduction benefit relative to a conventional engine installation for a large transport aircraft at current technology levels. The objective of the research task was to assess a $\mathrm{BLI}^{2} \mathrm{DTF}$ system relative to that potential fuel burn benefit. This assessment was done by 1) collecting performance data from the wind tunnel test of the boundary-layer-ingesting propulsor; 2) using those data to determine inlet recovery, fan stage pressure and temperature ratios, and fan stage efficiency; and 3) determining the overall propulsive efficiency and through system studies, fuel burn of a candidate vehicle through a simulated mission profile.

The primary research objective of the $\mathrm{BLI}^{2} \mathrm{DTF}$ wind tunnel experiment was to acquire fan-stage performance data at cruise conditions. Secondary research objectives included obtaining fan-stage performance data at other fan conditions, collecting data to determine the stall margin along the operating line, and assessing the operability of the fan over a wide range of conditions, noting areas of aerodynamic or aeromechanical instability.

A key to meeting these objectives was accurate measurement of the flow conditions upstream and downstream of the fan stage. To accomplish this, two rotating rake arrays were included in the experiment: the Aerodynamic Interface Plane Rotating Rake Array (AIPRRA) and the Fan-stage Exit Rotating Rake Array (FERRA). This paper will describe the process used by the authors to establish the number of rakes, probe types and spacing on those rakes, and the density of measurements circumferentially to adequately measure the flow field properties.

\section{Adiabatic Efficiency Challenges in the BLI²DTF Experiment}

The equation for adiabatic efficiency of a fan stage is:

$$
\eta_{A}=\frac{\frac{s_{P}{ }^{\frac{\gamma-1}{\gamma}}-1}{s_{T}-1}}{s}
$$

For pressure and temperature ratios near unity, the terms become small and sensitive to small errors as shown in fig. 3. Therefore, on a low-pressure-ratio fan, measuring fan stage adiabatic efficiency requires very accurate measurements of the total conditions both upstream and downstream of the fan stage. Hence, one of the key instrumentation systems of this successful test was a pair of rotating rake arrays, one each upstream and downstream of the fan stage. These arrays were rotated during fan operation to survey the flow fields entering and exiting the fan stage.

In a conventional fan system, performance parameters such as pressure and temperature ratios and adiabatic efficiency are calculated from averaged total pressure and temperature at the fan entrance and exit. The use of averaging and even the type of weighting used for averaging is generally not very important, as the flow fields measured are uniform enough that the resulting values are nearly identical. For a highly distorted fan flow, such as that ingested by the $\mathrm{BLI}^{2} \mathrm{DTF}$ fan, however, this is not the case.

\section{Design of the Rake Arrays}

Figure 4 shows a front view of the BLI ${ }^{2} \mathrm{DTF}$ propulsor. Figure 5 shows a close-up view of the portion of the experimental apparatus most relevant to this study. Shown from forward to aft are 1) AIPRRA, 2) fan, 3) Exit Guide Vanes (EGVs), and 4) FERRA.

American Institute of Aeronautics and Astronautics 
The designs of the AIPRRA and FERRA were based on a similar, smaller-diameter rotating rake array used in previous experiments. As shown in fig. 6, the rakes were fixed to a cylindrical spool, projecting inward from the casing toward the hub. The spool which was driven by a geared motor, which was capable of rotating the rakes during fan operation. The rakes were equally spaced circumferentially with probes arranged along the centerline of each rake. All measurements were made at the same axial plane. Pressure tubes from the rakes were routed to transducer modules mounted on the outer surface of the spool, while wires from thermocouples and dynamic pressure transducers were routed to modules external to the model. All wires and tubes going from the spool to external destinations were contained in a flexible cable carrier with a $U$-shaped bend, allowing array rotation of $\pm 140^{\circ}$. Wherever practical, the designs of the AIPRRA and FERRA were identical. However, some factors which influenced the design of the rotating rake arrays were unique to either the AIPRRA or FERRA.

\section{A. Common Factors Influencing Both Rotating Rake Array Designs}

Compactness - it was important to keep the axial length of the rotating rake arrays short. For the AIPRRA this requirement stems from the need to keep the inlet and fan together as they were designed to be closely-coupled. To this end, the wind tunnel experiment included configurations 1) with the full AIPRRA, 2) with the AIPRRA spool but no rakes, and 3) without the AIPRRA to determine the effect of the AIPRRA on the experiment. For the FERRA, a long axial length might have reduced the space available for the nozzle.

Instrumentation Routing - The amount of instrumentation was limited by the size of passages to route the instrumentation tubes and wires from the sensor to the data acquisition system. For the rotating rake arrays the limiting locations were the passages within the rakes (designed to have adequate wall thickness to withstand testing and to limit duct blockage) and around the perimeter of the rotating rake array spools (designed to limit test section blockage). To counter these limitations, all of the desired radial measurement positions were spread across multiple rake types, and the rake array was rotated to allow each of the rake types to sample at each circumferential location. In addition to effectively increasing the radial resolution of the measurement grid, for the FERRA this approach enabled nonsimultaneous measurement of total pressure and total temperature at the same locations.

Probe Interference - It was necessary to have a minimum distance between rake probes to prevent one probe from influencing its neighbors' measurements.

\section{B. Specific Factors Influencing the AIPRRA Design}

Spinner - The hub at the AIPRRA was part of an extended spinner which rotated with the fan. Therefore it was impractical to measure static pressure at the hub.

ARP 1420 - For comparison with historical AIP data, conformance with the ARP $1420^{5}$ standard for probe placement was required. ARP 1420 specifies a pattern of 40 measurement locations for calculating distortion, five rings with measurements at eight circumferential locations, with all locations at the centers of equal-area zones. Additionally, because dynamic distortion levels were of interest in this experiment, both steady and dynamic total pressures were measured at these locations.

Temperatures - The total temperatures at the AIP were assumed to be nearly uniform. Therefore, only one thermocouple was present in each AIPRRA rake.

Flow Angularity - Computational Fluid Dynamics (CFD) predictions showed up to $\pm 25^{\circ}$ flow angularity, albeit this angularity was mostly confined to the region near the centerline at the bottom of the inlet. For this reason, a threehole flow angularity probe was included on each AIPRRA rake. By comparison, the predicted flow angularity at the FERRA plane was no more than $\pm 4^{\circ}$.

Risk to the Fan - The presence of rakes upstream of a fan carries a risk of damage to the fan should any part of a rake separate. To mitigate this risk, special attention was given to the design and analysis of a strong rake, and a unique vibration-damping mounting system was developed.

\section{Specific Factors Influencing the FERRA Design}

Flow Measurement - It was determined that the most accurate method of air flow measurement for this experiment was by integration of the measured conditions at the FERRA. Therefore it was necessary to analyze the FERRA measurements with respect to the mass flow as well as the average total pressure and total temperature conditions.

Axial Location - With static pressure measurements only at the hub and casing, flow measurement at the FERRA becomes highly dependent on the assumption that the static pressure at interior points can be estimated from those measurements. As the flow exits the EGVs the static pressure varies greatly. Downstream, the variations in static

American Institute of Aeronautics and Astronautics 
pressure dissipate. Therefore, it was necessary to determine the effect of the axial location on the measurement of weight flow.

\section{Details of the Rotating Rake Array Designs}

There were two types of AIPRRA rakes, labelled 176 and 177, which differed in the arrangement and spacing of the rake probes, as shown in fig. 7 and Table 1. Instrumentation on the AIPRRA rakes consisted of five Prati ${ }^{6}$ probes (a combination total pressure probe housing a dynamic pressure transducer and a steady state pressure tube), four pitot probes, one total temperature probe, and one three-hole flow angularity probe. All probes except the angularity probe and the pitot probe nearest the base on rake type 176 were enclosed in $\mathrm{Kiel}^{7}$ shields.

Table 1. Arrangement of Probes on the AIPRRA Rakes

\begin{tabular}{|c|c|c|}
\hline \multirow{2}{*}{ Tube Type } & \multicolumn{2}{|c|}{ Radius, in } \\
\cline { 2 - 3 } & Rake 176 & Rake 177 \\
\hline $\mathrm{P}_{\mathrm{T}}$ & 3.727 & 3.492 \\
\hline Prati & 4.620 & 4.620 \\
\hline $\mathrm{P}_{\mathrm{T}}$ & 6.022 & 5.367 \\
\hline $\mathrm{T}_{\mathrm{T}}$ & -- & 5.962 \\
\hline Prati & 6.612 & 6.612 \\
\hline 3 Hole & -- & 7.082 \\
\hline $\mathrm{P}_{\mathrm{T}}$ & 7.348 & -- \\
\hline Prati & 8.130 & 8.130 \\
\hline $\mathrm{T}_{\mathrm{T}}$ & 8.766 & -- \\
\hline $\mathrm{P}_{\mathrm{T}}$ & -- & 8.848 \\
\hline Prati $_{3}$ & 9.406 & 9.406 \\
\hline $3 \mathrm{Hole}_{\mathrm{y}}$ & 9.876 & -- \\
\hline $\mathrm{P}_{\mathrm{T}}$ & -- & 9.968 \\
\hline Prati & 10.529 & 10.529 \\
\hline $\mathrm{P}_{\mathrm{T}}$ & 10.855 & -- \\
\hline
\end{tabular}

The number of the AIPRRA rakes was set at eight, and five Prati probes were placed at the centers of equal-area regions. All other probes on the AIPRRA rakes were then placed where the probe-to-probe interference criteria would permit.

Instrumention on the FERRA rakes consisted typically of an equal number of total pressure and total temperature probes arranged in alternating fashion. Examples of the FERRA rakes are shown in fig. 8. Depicted are two types of rake, labelled 273 and 274. Two additional types, 275 and 276, had probes in the same locations as 273 and 274, except that the pitot and total temperature probes were reversed, and type 275 lacked a total temperature probe nearest the base of the rake. Table 2 describes the arrangement of probes on the FERRA rakes in further detail. All probes except the pitot probe nearest the base on rake type 273 were Kiel probes to allow accurate measurement of total conditions even in the presence of non-axial flow.

American Institute of Aeronautics and Astronautics 
Table 2. Arrangement of Probes on the FERRA Rakes

\begin{tabular}{|c|c|c||c|c|c|}
\hline \multirow{2}{*}{ Radius, in } & \multicolumn{2}{|c|}{ Tube Type } & \multirow{2}{*}{ Tyene } & \multicolumn{2}{c|}{ Tube Type } \\
\cline { 2 - 3 } \cline { 5 - 6 } & Rake 273 & Rake 275 & Radius, in & Rake 274 & Rake 275 \\
\hline 5.530 & $\mathrm{~T}_{\mathrm{T}}$ & $\mathrm{P}_{\mathrm{T}}$ & 5.220 & $\mathrm{~T}_{\mathrm{T}}$ & $\mathrm{P}_{\mathrm{T}}$ \\
\hline 6.151 & $\mathrm{P}_{\mathrm{T}}$ & $\mathrm{T}_{\mathrm{T}}$ & 5.840 & $\mathrm{P}_{\mathrm{T}}$ & $\mathrm{T}_{\mathrm{T}}$ \\
\hline 6.771 & $\mathrm{~T}_{\mathrm{T}}$ & $\mathrm{P}_{\mathrm{T}}$ & 6.462 & $\mathrm{~T}_{\mathrm{T}}$ & $\mathrm{P}_{\mathrm{T}}$ \\
\hline 7.384 & $\mathrm{P}_{\mathrm{T}}$ & $\mathrm{T}_{\mathrm{T}}$ & 7.079 & $\mathrm{P}_{\mathrm{T}}$ & $\mathrm{T}_{\mathrm{T}}$ \\
\hline 7.981 & $\mathrm{~T}_{\mathrm{T}}$ & $\mathrm{P}_{\mathrm{T}}$ & 7.685 & $\mathrm{~T}_{\mathrm{T}}$ & $\mathrm{P}_{\mathrm{T}}$ \\
\hline 8.554 & $\mathrm{P}_{\mathrm{T}}$ & $\mathrm{T}_{\mathrm{T}}$ & 8.271 & $\mathrm{P}_{\mathrm{T}}$ & $\mathrm{T}_{\mathrm{T}}$ \\
\hline 9.093 & $\mathrm{~T}_{\mathrm{T}}$ & $\mathrm{P}_{\mathrm{T}}$ & 8.828 & $\mathrm{~T}_{\mathrm{T}}$ & $\mathrm{P}_{\mathrm{T}}$ \\
\hline 9.593 & $\mathrm{P}_{\mathrm{T}}$ & $\mathrm{T}_{\mathrm{T}}$ & 9.349 & $\mathrm{P}_{\mathrm{T}}$ & $\mathrm{T}_{\mathrm{T}}$ \\
\hline 10.049 & $\mathrm{~T}_{\mathrm{T}}$ & $\mathrm{P}_{\mathrm{T}}$ & 9.827 & $\mathrm{~T}_{\mathrm{T}}$ & $\mathrm{P}_{\mathrm{T}}$ \\
\hline 10.457 & $\mathrm{P}_{\mathrm{T}}$ & $\mathrm{T}_{\mathrm{T}}$ & 10.259 & $\mathrm{P}_{\mathrm{T}}$ & $\mathrm{T}_{\mathrm{T}}$ \\
\hline 10.816 & $\mathrm{~T}_{\mathrm{T}}$ & $\mathrm{P}_{\mathrm{T}}$ & 10.643 & $\mathrm{~T}_{\mathrm{T}}$ & $\mathrm{P}_{\mathrm{T}}$ \\
\hline 11.050 & $\mathrm{P}_{\mathrm{T}}$ & -- & 10.978 & $\mathrm{P}_{\mathrm{T}}$ & $\mathrm{T}_{\mathrm{T}}$ \\
\hline
\end{tabular}

Static pressure ports were located at the base of each rake, at the probe measurement plane on the casing surface of the rotating rake spool. For the FERRA, static pressure ports were also located along the hub surface at the probe measurement plane. For the AIPRRA, there were no static-pressure ports on the hub.

\section{Simulated Surveys Using CFD Datasets}

The objectives of the simulated surveys were two-fold: to establish appropriate array geometry and operating procedures to meet test objectives, and to assess the impact of these choices on the overall uncertainty of the surveyed data.

In an effort to determine appropriate spacing of sensors on the survey rakes and to establish required survey density, the authors developed software to simulate rake surveys by sampling from pre-test CFD solutions. CFD cases used for this study came from time-accurate, full-circumference solutions by UTRC, using UTCFD, a Reynoldsaveraged Navier-Stokes solver using the k- $\omega$ turbulence model. To reduce the complexity of the study and better reflect steady-state data acquisition to be used in the subsequent wind tunnel experiment, the CFD solutions were time-averaged.

Two rounds of simulations were used. The first round, based on CFD of a conventional inlet and fan exposed to an ingested boundary layer, was performed while awaiting the completion of the BLI ${ }^{2}$ DTF fan design and accompanying CFD. These simulated surveys were used to test the software and draw some initial conclusions about the FERRA design. The primary variables in these initial explorations were the number of circumferential measurements using an eight-rake array and the number of radial measurements. Table 3 summarizes these variables.

Table 3. Conditions Simulated in the Round 1 FERRA Study

\begin{tabular}{|c|c|}
\hline Variable & Values \\
\hline Number of radial measurements & 2 to 12 in increments of 2 \\
\hline Number of circumferential measurements & 8 to 176 in increments of 8 \\
\hline
\end{tabular}

The second round of survey simulatons was based on CFD of the BLI ${ }^{2}$ DTF inlet and fan stage. The relevant conditions from the second-round CFD are shown in fig. 9. These surveys further explored the FERRA design with more detailed exploration of the parametric variables summarized in Table 4. Each of these variables was selected to answer questions related to the FERRA design. Additional surveys also explored the AIPRRA design, which was more constrained than the FERRA. Because of these constraints, the AIPRRA survey simulations examined specific arrangements of rake probes rather than broader explorations of multiple design parameters. The results of the second round surveys were used to determine the contribution of the survey process to the uncertainties of the aerodynamic-

American Institute of Aeronautics and Astronautics 
interface-plane and fan-stage-exit-plane average total pressures and total temperatures, leading to an assessment of the overall uncertainty of the adiabatic efficiency measurements.

Table 4. Conditions Simulated in the Round 2 FERRA Study

\begin{tabular}{|c|c|}
\hline Variable & Values \\
\hline Axial Station & $\begin{array}{c}14.1 ", 14.6 ", 15.2 ", 15.6 ", 16.1 " \\
\text { downstream of fan stacking axis }\end{array}$ \\
\hline Number of circumferential measurements & 9 to 153 in increments of 9 \\
\hline Number of radial measurements & $6,12,18$ \\
\hline Stretch factor, $\mathrm{f}_{\mathrm{s}}$ & $0.125,0.25,0.5,0.75,1.0$ \\
\hline
\end{tabular}

The following paragraphs describe the processing of the simulated survey data. Figure 10 shows a flowchart of the survey algorithm. The large letters in the figure are used to refer to steps in the process.

In step A the CFD data was read, relevant variables such as total and static pressures and temperatures, and velocities were calculated. From these, elemental mass flow rates were calculated and summed across the measurement planes.

Each combination of the variables in the tables above was referred to as a case. For each case (step B), the distributions of probes, i.e. their radial positions on each rake, were calculated. For each pressure probe, including the static pressure ports at the walls, a portion of the annulus area was assigned to the probe as described in Eq. 2 and illustrated in fig. 11. This formulation sets the dividing line between areas as the average of $\mathrm{r}^{2}$ values of the adjacent probes.

$$
A_{i}=\left\{\begin{array}{lr}
\frac{\pi\left(r_{1}^{2}-r_{0}^{2}\right)}{2 m} & \text { for } i=0(\text { hub }) \\
\frac{\pi\left(r_{i+1}^{2}-r_{i-1}^{2}\right)}{2 m} & \text { for } 1 \leq i \leq n \\
\frac{\pi\left(r_{n+1}^{2}-r_{n}^{2}\right)}{2 m} & \text { for } i=n+1(\text { casing })
\end{array}\right.
$$

The baseline distribution of probes on the rakes was at the centers of equal areas. A hyperbolic tangent function was applied to the baseline distribution using the method of Vinokur ${ }^{8}$, where the change to the distribution was specified by a "stretch factor". This stretch factor was a multiplier for the spacing between the first probe on each end of the rake and the nearby wall. That is, a stretch factor of 1.0 indicates unmodified equal-area distribution, while a stretch factor of 0.125 indicates dense packing toward the ends of the rakes.

$$
f_{S}=\left\{\begin{array}{lc}
\frac{\left.\left(r_{1}-r_{0}\right)\right|_{\text {stretched }}}{\left.\left(r_{1}-r_{0}\right)\right|_{\text {unstretched }}} & \text { for } i=0(\text { hub }) \\
\frac{\left.\left(r_{n+1}-r_{n}\right)\right|_{\text {stretched }}}{\left.\left(r_{n+1}-r_{n}\right)\right|_{\text {unstretched }}} & \text { for } i=n+1(\text { casing })
\end{array}\right.
$$

For the rakes both in the experiment and in the simulated surveys, static pressure was only measured at the end walls. From the rake geometries and sampled pressures and temperatures, areas and mass flux were calculated for each measurement location, and these were used to calculate area-weighted and mass-flux-weighted average total pressure and temperature for the fan entrance and exit planes. The area-weighted averages were intended as an alternative to more intensive mass-weighted average calculations. However, it was determined that the mass-weighted averages are more correct from a thermodynamic perspective, so only the mass-weighted averages will be discussed.

The simulated surveys were performed at multiple starting locations in the circumferential direction, to simulate the effect of positional errors on the measured pressures and temperatures. These locations are referred to as "offsets" in step C. The goal of these studies was to find a combination of design and operational parameters where the effects of these positional errors, as measured by the standard deviation of the measured values, were minimized.

The angular position of each of the eight AIPRRA or nine FERRA rakes was calculate in step D. Then casing and hub (for the FERRA) static pressures were calculated by interpolation from the CFD flowfield. This and all other interpolations of the CFD data to probe locations were calculated by the method of Keys ${ }^{9}$ for interior cells in the CFD grid and by linear interpolation for edge cells.

American Institute of Aeronautics and Astronautics 
Static pressure was measured at the hub and case in the FERRA, but only at the case for the AIPRRA. Therefore, static pressure at each of the rake probe positions was calculated by linear interpolation for the FERRA, whereas for the AIPRRA the case pressure was extrapolated as a constant across the rake. Additional static pressure measurements were available on the AIPRRA with the inclusion of three-hole flow angularity probes, but these probes were added to the design later and were not included in this study. To examine the implications of the assumption of a uniform static pressure in the radial direction, a separate calculation of the mass-averaged total pressure and total temperature was made using the local static pressure from the CFD solution. This change was found to have a minimal effect on the averages. The greatest gradient in static pressure in the radial direction was observed to be in the near-wall regions, where velocities were low and therefore their effect on mass-weighted quantities was limited.

The total pressure, total temperature, and static pressure were calculated in step E by interpolation from the CFD data. An alternate calculation of the static pressure was calculated in step F by linear interpolation of the hub and casing values for the FERRA or simply as the casing value for the AIPRRA.

For the AIPRRA, data from the total temperature probes were interpolated/extrapolated to all of the pressure probe locations. For those pressure probes where temperature data was available on either side, radially, a linear interpolation was used. For those pressure probes where temperature data was available only on one side, that temperature value was used. This extrapolation was justified by the assumption that the total temperatures should be reasonably uniform. This sub-step was not necessary for the FERRA as the total temperature probes were placed at the same radial locations as the total pressure probes.

Mach number and elemental mass flow rate at each probe location were calculated in step G. These calculations were done for both static pressures calculated in steps E and F. Mach number was calculated from static and total pressure as:

$$
M=\sqrt{\frac{2}{\gamma-1}\left[\left(\frac{P_{T}}{P_{S}}\right)^{\frac{\gamma-1}{\gamma}}-1\right]}
$$

Mass flow rate was calculated as:

$$
\dot{m}=\sqrt{\frac{\gamma\left(1+\frac{\gamma-1}{2} M^{2}\right)}{R T_{T}}} P_{S} M A
$$

Note that this formulation does not account for flow angularity, since the angularity probes were added to the design after this study. Mass-averaged quantities of total pressure and total temperature were calculated as:

$$
\bar{Q}=\frac{\sum Q_{i} \dot{m}_{i}}{\sum \dot{m}_{i}}
$$

\section{Results of the Simulated Surveys}

One topic of interest when using rotating rakes in a periodic flow field is the influence of starting position of the rakes on repeatability of the measured pressures and temperatures of the survey. For this reason, both rounds of survey simulations were conducted at multiple starting positions, and the standard deviations of the measurements of total pressure and total temperature were assessed.

Figures 12 and 13 show these standard deviations for a set of FERRA rakes in the first round simulated surveys as a function of the measurement density in the circumferential (x-axis) and radial (different symbols) directions. In fig. 12a, total pressure standard deviations are shown for a FERRA with eight rakes. From the figure it is clear that standard deviation follows a decaying curve, but there are spikes in the curve. These spikes correspond to integer multiples of the $56 \mathrm{EGVs}$ of the first round configuration. Figure $12 \mathrm{~b}$ shows the same results, except the number of FERRA rakes was nine. The spikes are greatly reduced or avoided altogether. Figure 13 shows the same comparison for total temperatures. While less dramatic, this plot shows a similar reduction in standard deviations.

American Institute of Aeronautics and Astronautics 
To better understand the results shown in figs. 12 and 13, imagine a simplified flowfield, represented in fig. 14 . The grey bars represent diminished pressure in the wakes of 8 evenly spaced vanes. If we sample the flow field at 8 evenly spaced points, marked "A" in the figure, we will be sampling only from the wakes, and the averages of the sample will be biased low. If we sample from 8 evenly spaced points, marked "B", we will be sampling only from the undisturbed flow between wakes and the averages of the sample will be biased high. The result of our sampling will be highly dependent on the starting position of our sample pattern and the standard deviation of multiple sample patterns will be high. We will refer to this case as "in-phase" sampling. If, on the other hand, we sample at 9 evenly spaced points, marked "C", we will sample from a variety of positions relative to the wakes and averages of the sample will be reasonably representative of the entire flowfield. We will refer to this case as "out-of-phase" sampling.

From the first round simulations, it is clear that in-phase sampling should be avoided. To address this, a decision was made to use a 9-rake FERRA. It should be noted that to resolve all of the wakes behind the EGVs would require an extensive set of samples, but that was not the objective of the measurement. The objective was to obtain sufficient samples such that the averages of the measured total pressures and total temperatures were representative of the FERRA-plane flowfield. A combination of the results from the first round study and design evaluations led to the determination of the number of probes per rake for both the AIPRRA (10-11 probes per rake) and FERRA (11-12 probes per rake).

Figure 15 shows results from the second round of the study, in which simulated surveys were performed on CFD for the BLI ${ }^{2} \mathrm{DTF}$ propulsor. Shown are standard deviations of mass flow, expressed as a percentage of the measured value, for a large number of parametric cases. Four parametric variables are explored. Each diamond-shaped cluster represents a set of surveys all at the same values on the primary axes. The lowest point in the diamond pattern represents the actual value on the primary axes (number of circumferential measurements and axial station). The rest of the points in the clusters represent variations in the secondary axes (number of circumferential measurements and stretch factor). The color of the points represent the values of the standard deviation in mass flow. As with the round one studies, the standard deviation was reduced with increasing measurement density in both the radial and circumferential directions. However, certain circumferential densities which were in phase or in-phase multiples of the number of EGVs show higher standard deviations. Axial station made relatively little difference in the results, especially for points downstream of the first station at 14.1". The improvement to standard deviation that was seen with axial station appears to be due to the flattening of the static pressure profile with increasing axial station.

Based on the results shown, the rakes were designed with a stretch factor of 0.5 , at a minimum axial station of 14.6 inches. The results shown suggest that 18 measurements be used in the radial direction. In the circumferential direction, a minimum of 54 measurements was recommended. This point is indicated by the arrow in the figure.

Uncertainty estimates for the adiabatic efficiency were calculated. As in the first round study, the samples in the second round study were obtained using multiple rake-array starting positions. The variance of these estimates from those of the CFD solution provided estimates of the uncertainty due to discretization of the AIPRRA and FERRA flow fields. These were combined with uncertainty estimates of the instruments - \pm 0.015 psi for absolute pressures and $\pm 0.9 \mathrm{R}$ for temperatures at the $95 \%$ confidence level - to calculate uncertainty estimates at the $95 \%$ confidence level using Eq. 7.

Figure 16 shows the results of adiabatic efficiency uncertainty calculations for the design cruise operating condition (100\% speed) and four "corner points", two each at $70 \%$ speed idle and $105 \%$ overspeed. The uncertainty grows as fan speed is reduced primarily because the fan pressure and temperature ratios at lower speeds are closer to unity. Thus, variations in those parameters have a greater effect on the calculated adiabatic efficiency.

Figure 17 shows the results of the mass flow rate uncertainty calculations for same points as fig. 16. For four of the five conditions the uncertainty values are virtually identical; for the choke point at idle, the value is approximately $5 \%$ higher. All of the values for uncertainty were deemed acceptable to meet the objectives of the BLI ${ }^{2} \mathrm{DTF}$ experiment.

$$
U_{f(a, b, \cdots)}=\sqrt{\left(\frac{\partial f}{\partial a}\right)^{2} U_{a}^{2}+\left(\frac{\partial f}{\partial b}\right)^{2} U_{b}^{2}+\cdots}
$$

\section{Comparison of the Surveyed Experiment to Surveyed CFD and the Full Resolution CFD}

Figures 18 and 19 show contours of total pressure and total temperature, respectively, at the AIPRRA plane for a) the BLI'DTF CFD, b) the BLI ${ }^{2}$ DTF CFD interpolated onto the experimental probe locations, and c) the BLI ${ }^{2}$ DTF experimental data corrected to the CFD freestream conditions. The CFD and CFD interpolated plots suggest that the loss of resolution when sampling the flowfield does not significantly alter the shape of the contours within the region

American Institute of Aeronautics and Astronautics 
covered by the experimental grid. There are some differences between the CFD and the experimental results. The boundary layer in the experiment appears to be thicker, and the range of pressures appears smaller, suggesting a lower overall distortion level. However, the shape of the distortion region is similar between the CFD and experiment. The radial density of the experimental measurements was sufficient to capture several points in the boundary layer.

Figures 20 and 21 show contours of total pressure and total temperature, respectively, at the FERRA plane for a) the $\mathrm{BLI}^{2} \mathrm{DTF}$ CFD, b) the BLI ${ }^{2} \mathrm{DTF}$ CFD interpolated onto the experimental probe locations, and c) the BLI ${ }^{2} \mathrm{DTF}$ experimental data corrected to the CFD freestream conditions. The experimental grid, while relatively dense for turbomachinery measurements, was insufficiently dense circumferentially to capture the wakes of all 56 EGVs. Nevertheless, survey results show that the calculated average conditions and mass flow rate can be calculated accurately from this level of detail. Further, while somewhat different in pressure values, the CFD predicted the shape of the flow structures. This finding leads the authors to assert that the results obtained in the simulated surveys is representative of the actual surveys for the purpose of averaging.

\section{Conclusions}

Low pressure ratio fans require precise performance measurements for accurate calculations of fan-stage performance. Rotating rake arrays provide a means to make precise measurements, but certain cautions should be observed. First, if the array is downstream of the fan stage, the number and/or placement of the rakes should be adjusted to ensure that they do not correspond with the number and/or positions of wakes and other flow features (i.e. "in-phase" measurements). For this reason, the wakes of the EGVs strongly influenced the design of the FERRA. Second, the density of measurements in the radial and circumferential directions is the next-most-important factor in reducing measurement error. Using heterogeneous rake probe arrangements allowed for sampling the experimental flowfield at sufficient resolution to achieve accurate measurement of the total pressures, total temperatures, and mass flow rate in the experiment. CFD solutions provide a valuable resource for determining the required resolution.

\section{Acknowledgements}

This effort was supported by NASA's Advanced Air Transport Technology Project. The authors would like to thank our team members at the United Technologies Research Center for their contributions, including ideas and constructive criticisms which made this work better, as well as the design engineers at NASA and Vantage Partners, Limited, who turned the results of this work into the AIPRRA and FERRA mechanisms which were critical to our subsequent work.

\section{References}

${ }^{1}$ Plas, A.P. "Performance of a Boundary Layer Ingesting Propulsion System," Cambridge : MIT M.S. Thesis, 2006.

${ }^{2}$ Plas, A., Crichton, D., Sargeant, M., Hynes, T., Greitzer, E., Hall, C., and Madani, V., "Performance of a Boundary Layer Ingesting (BLI) Propulsion System," 45th AIAA Aerospace Sciences Meeting and Exhibit, AIAA Paper 2007-0450, Aug. 2007.

${ }^{3}$ Hardin, L., Tillman, G., Sharma, O., Berton, J., and Arend, D., “Aircraft System Study of Boundary Layer Ingesting Propulsion," 48th AIAA/ASME/SAE/ASEE Joint Propulsion Conference \& Exhibit, AIAA Paper 2012-3993.

${ }^{4}$ Ochs, S. S., Tillman, G., Joo, J., and Voytovych, D., "CFD-based Analysis of Boundary Layer Ingesting Propulsion," 51st AIAA/SAE/ASEE Joint Propulsion Conference, AIAA Paper 2015-3800, 2015.

5"Gas Turbine Engine Inlet Flow Distortion Guidelines," s.l. : Society of Automotive Engineers, April, 2017. Aerospace Recommended Practice. ARP 1420C.

${ }^{6}$ Arend, D. J. and Saunders, J. D. "An Experimental Evaluation of the Performance of Two Combination Pitot Probes,”. 2009. NASA TM-2009-215632.

${ }^{7}$ Vinokur, M., "On one-dimensional stretching functions for finite-difference calculations," Journal of Computational Physics, vol. 50, 1983, pp. 215-234.

${ }^{8}$ Keys, R., "Cubic convolution interpolation for digital image processing," IEEE Transactions on Acoustics, Speech, and Signal Processing, vol. 29, 1981, pp. 1153-1160.

${ }^{9}$ Kiel, G. "Total Head Meter with Small Sensitivity to Yaw", Technical Memorandum 775. Washington, DC: National Advisory Committee for Aeronautics, 1935.

American Institute of Aeronautics and Astronautics 


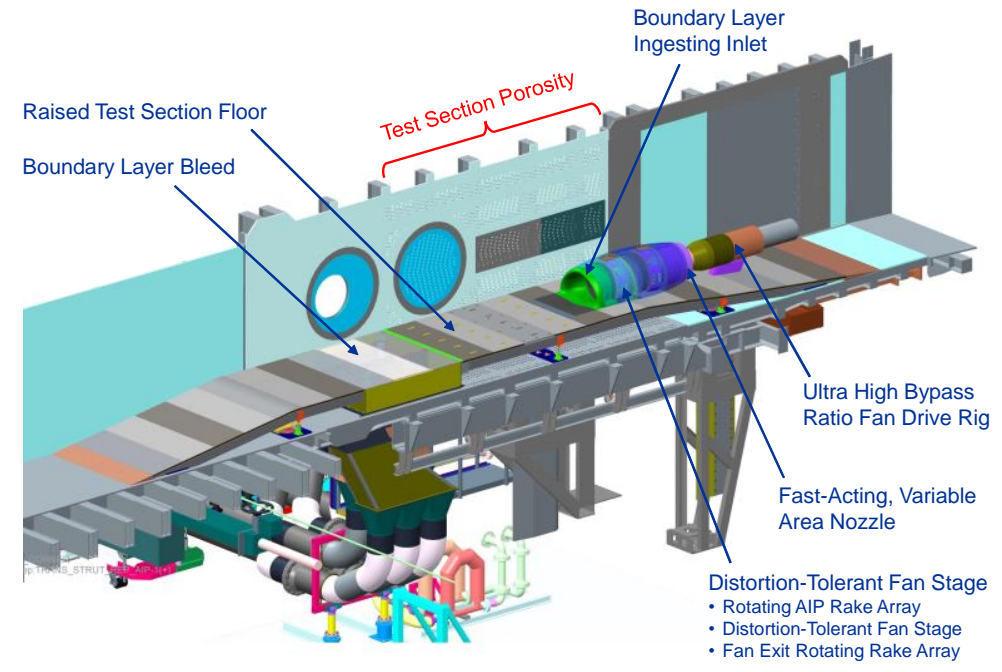

Figure 1. The BLI'DTF Experimental Setup in the 8x6 Wind Tunnel

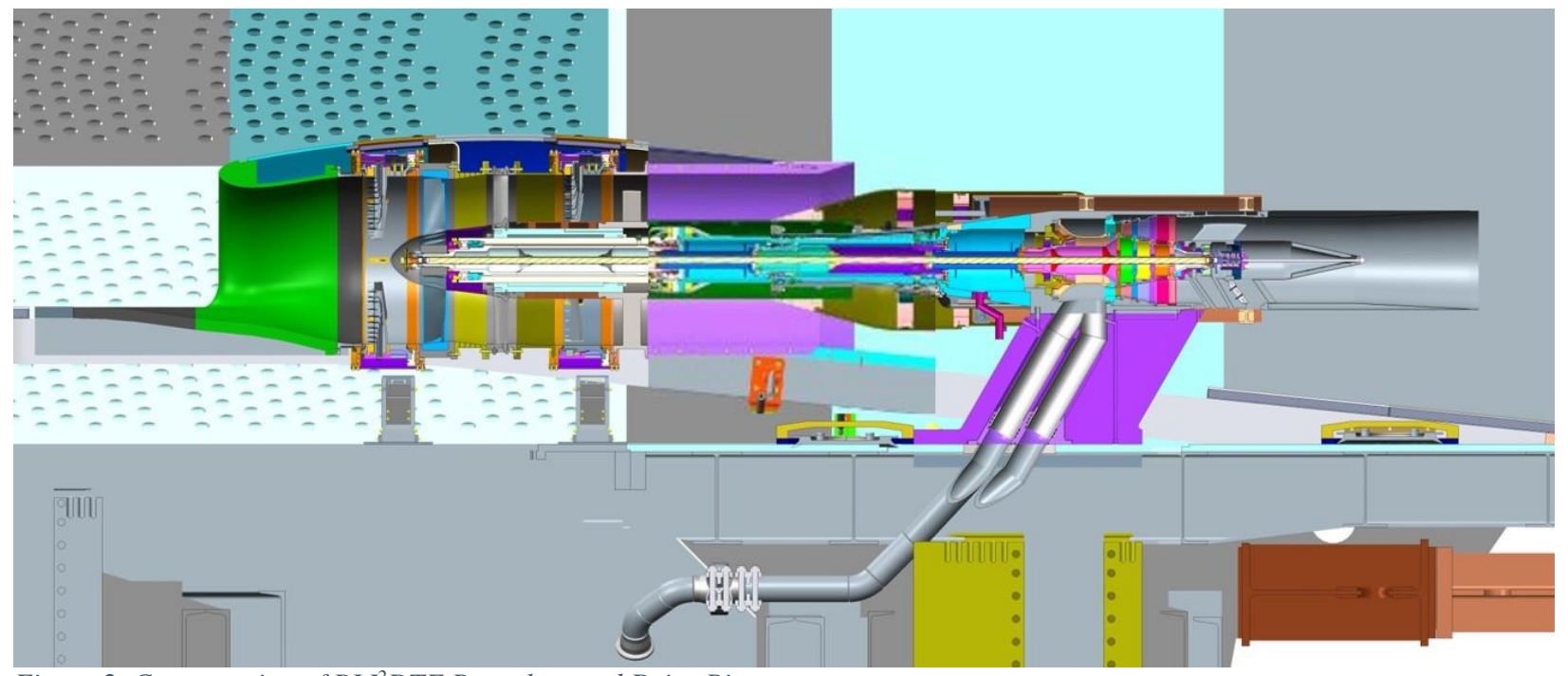

Figure 2. Cross-section of BLI DTF Propulsor and Drive Rig 


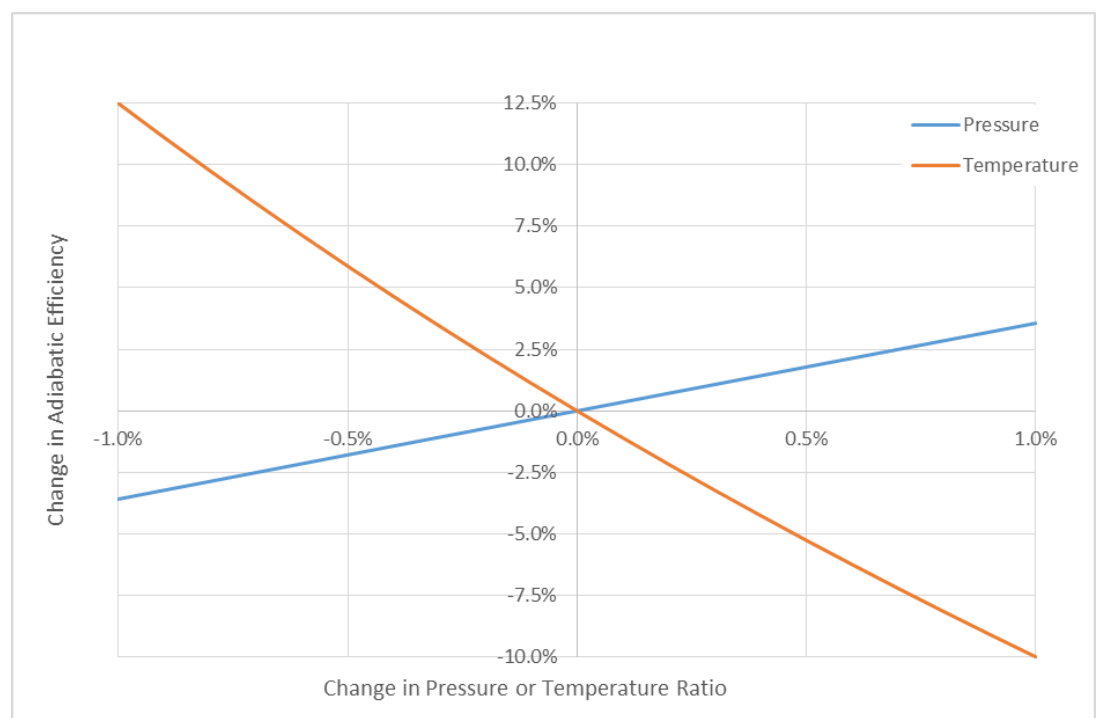

Figure 3 Sensitivity of Adiabatic Efficiency Calculation to Changes in Pressure and Temperature Ratios

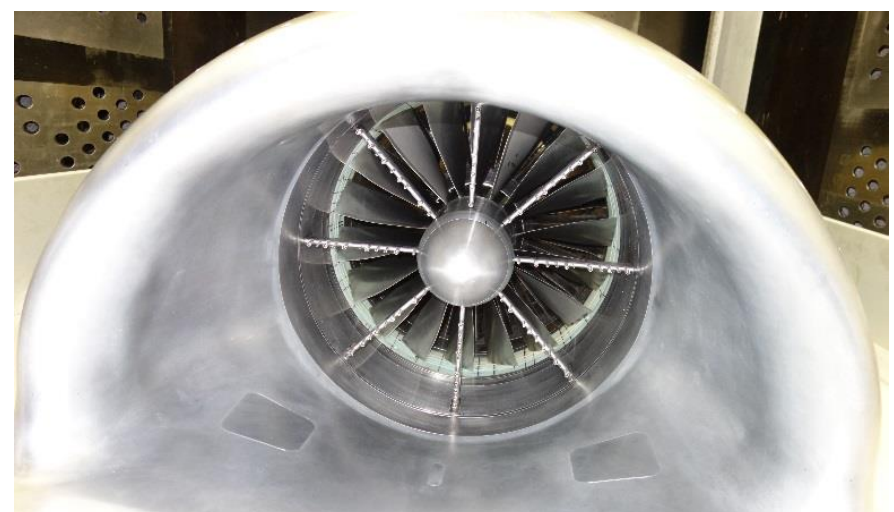

11182016

Figure 4. Front View of Propulsor with AIP Rakes Installed

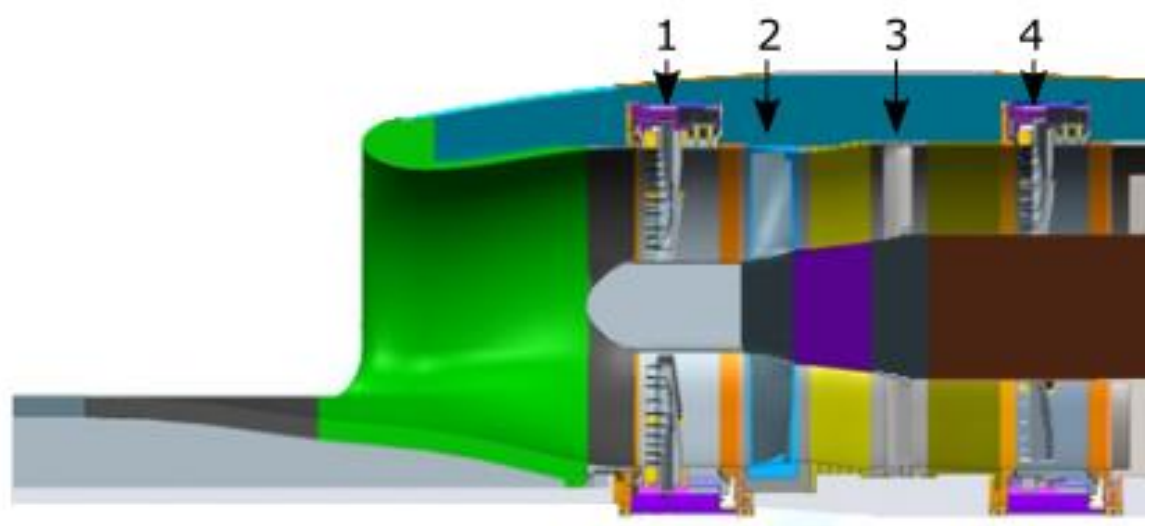

Figure 5. Region of Primary Interest, Showing 1) AIPRRA, 2) Fan, 3) EGVs, and 4) FERRA 


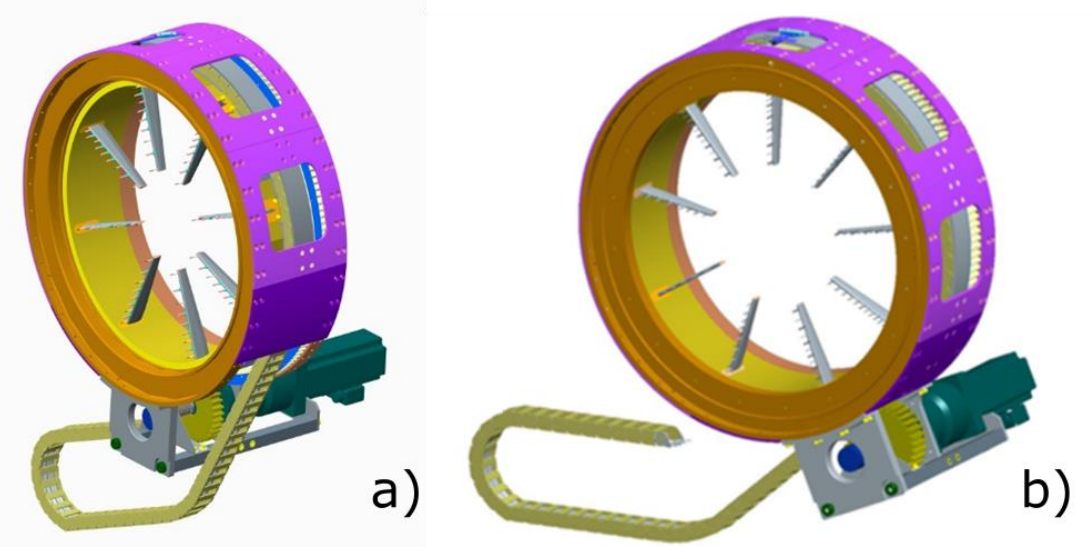

Figure 6. Rotating Rake Arrays; a) AIPRRA, b) FERRA
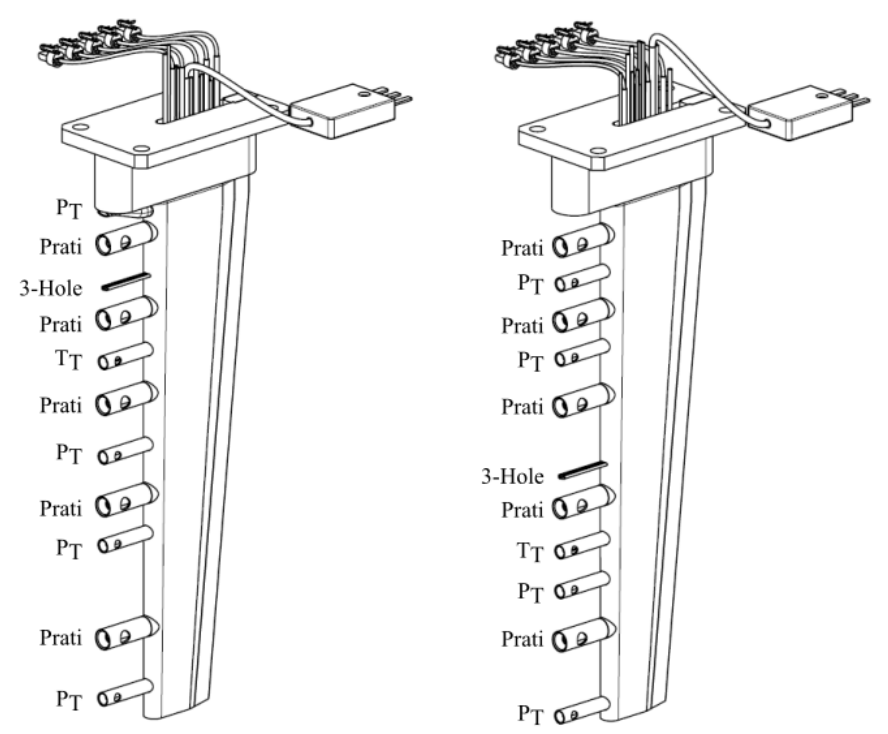

Figure 7. AIPRRA Type 176 (left) and 177 (right) Rakes
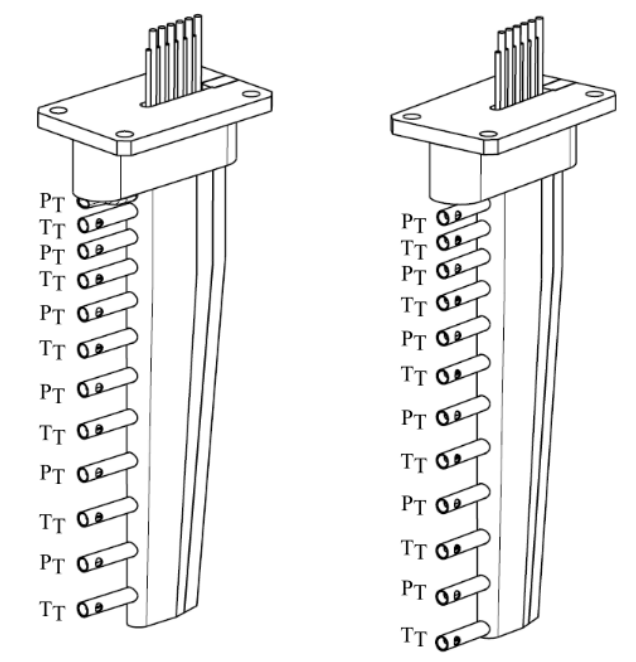

Figure 8. FERRA Type 273 (left) and 274 (right) Rakes

American Institute of Aeronautics and Astronautics 


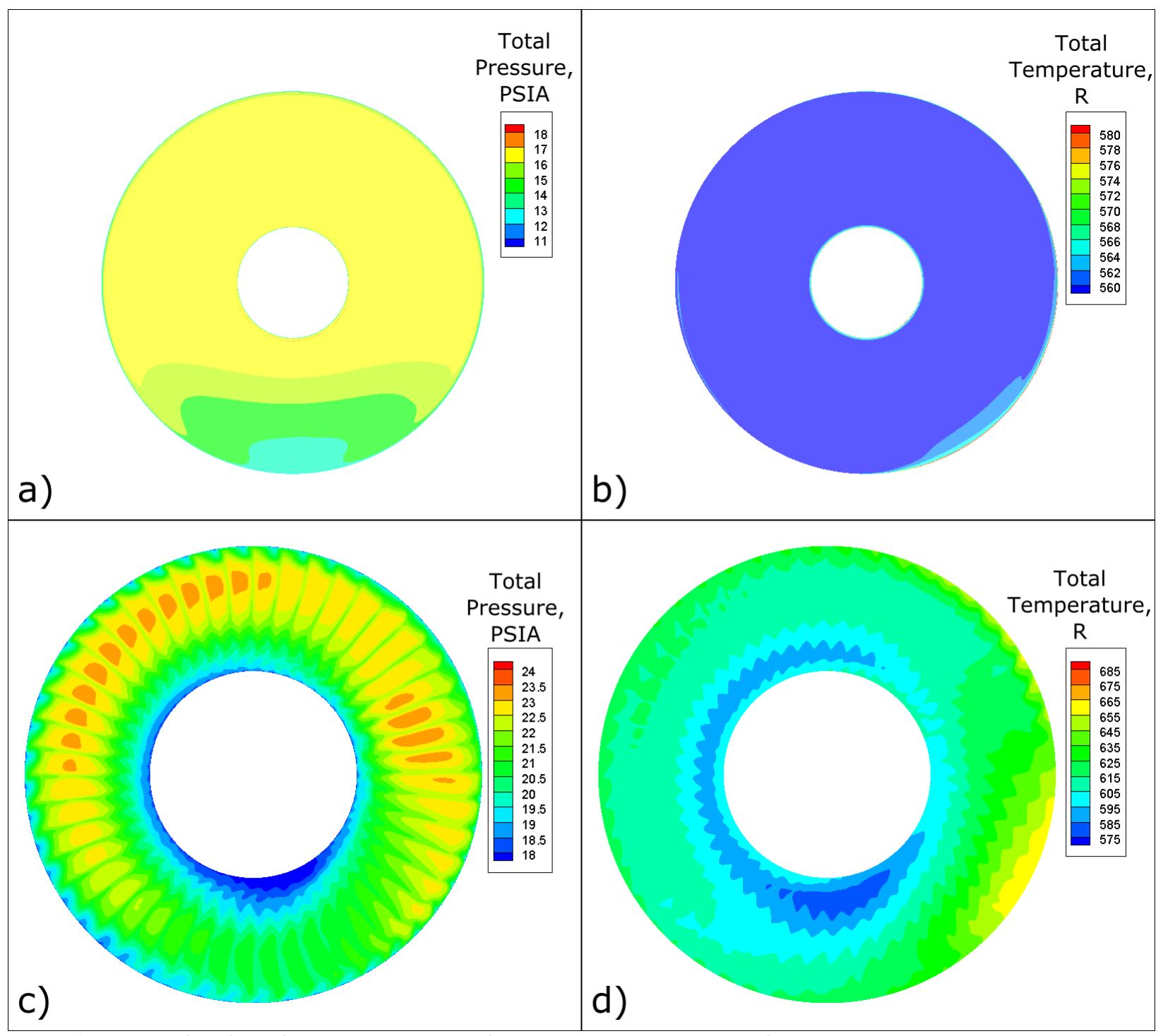

Figure 9. CFD Predicted Conditions. a) AIPRRA PT, b) AIPRRA TT, c) FERRA PT, d) FERRA TT 


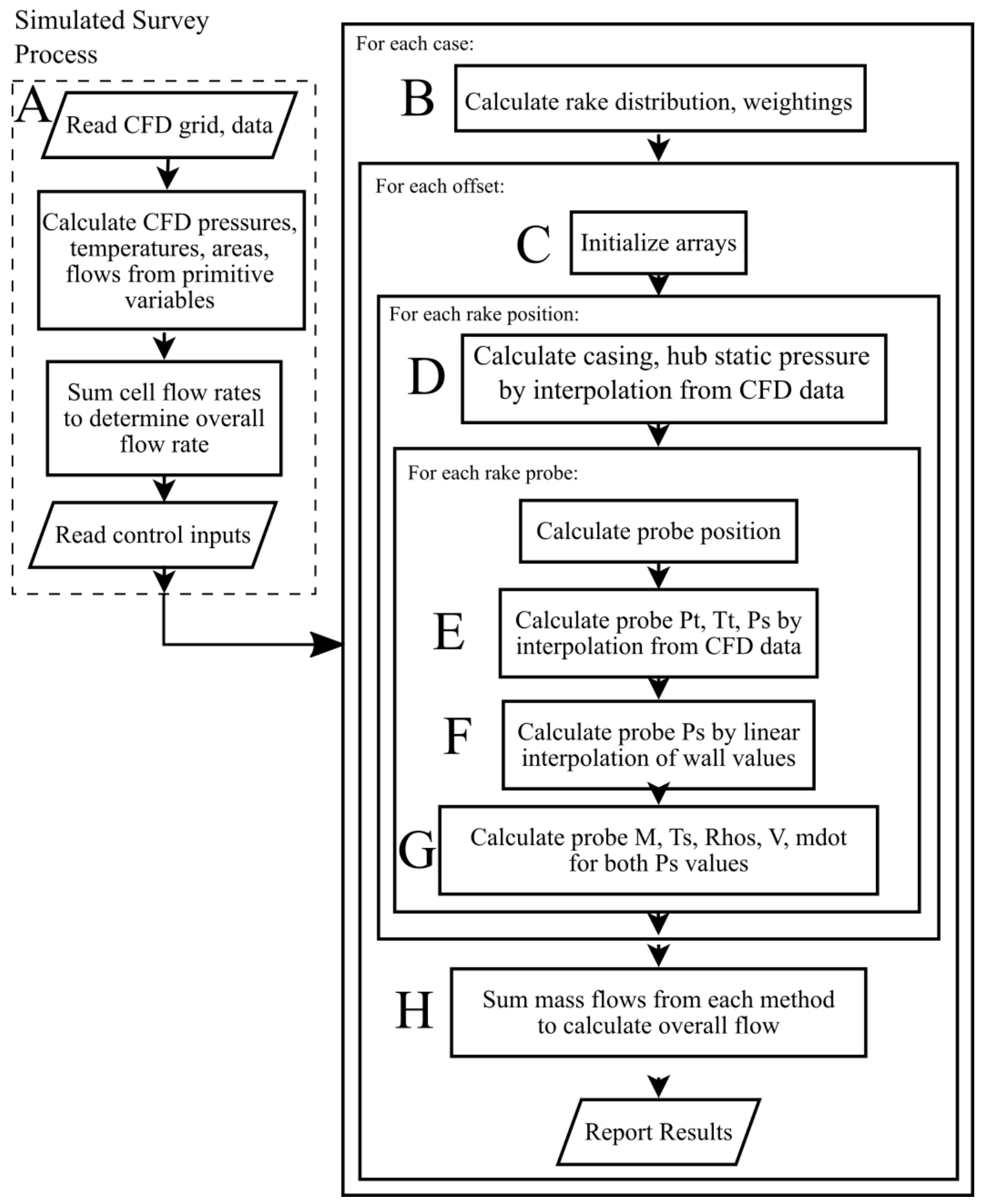

Figure 10. Flowchart of the CFD Sampling and Analysis Algorithm 


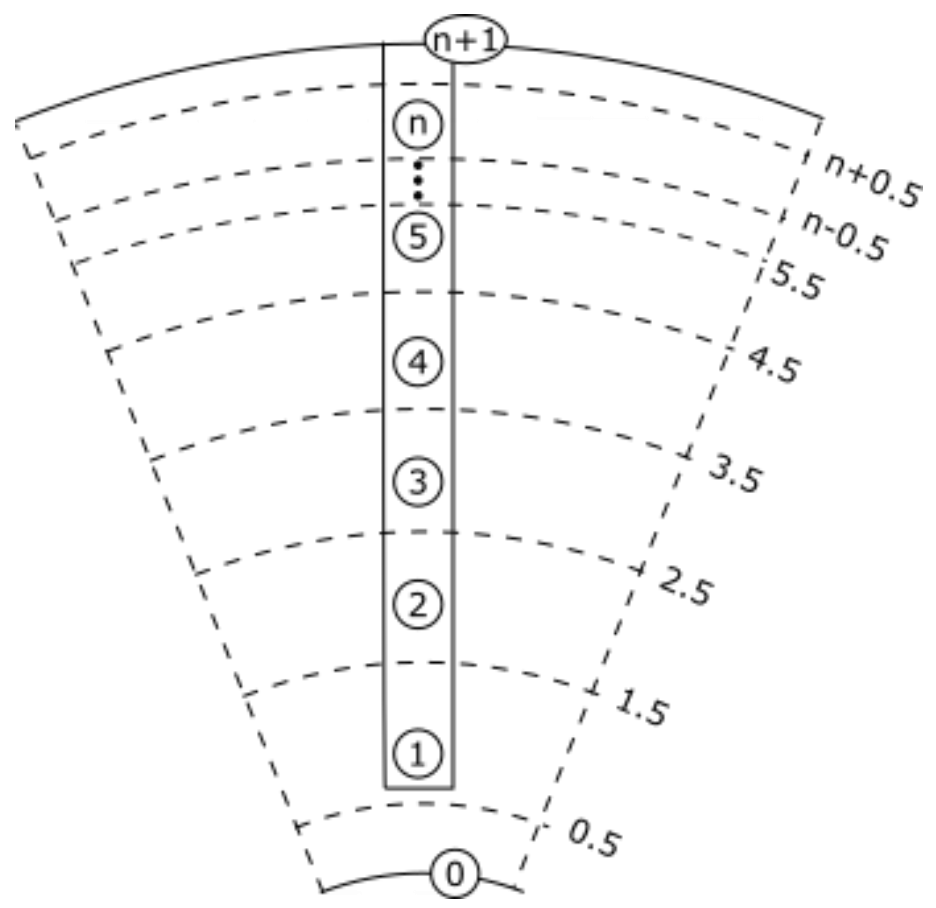

Figure 11. Assignment of Areas for Pressure Probes
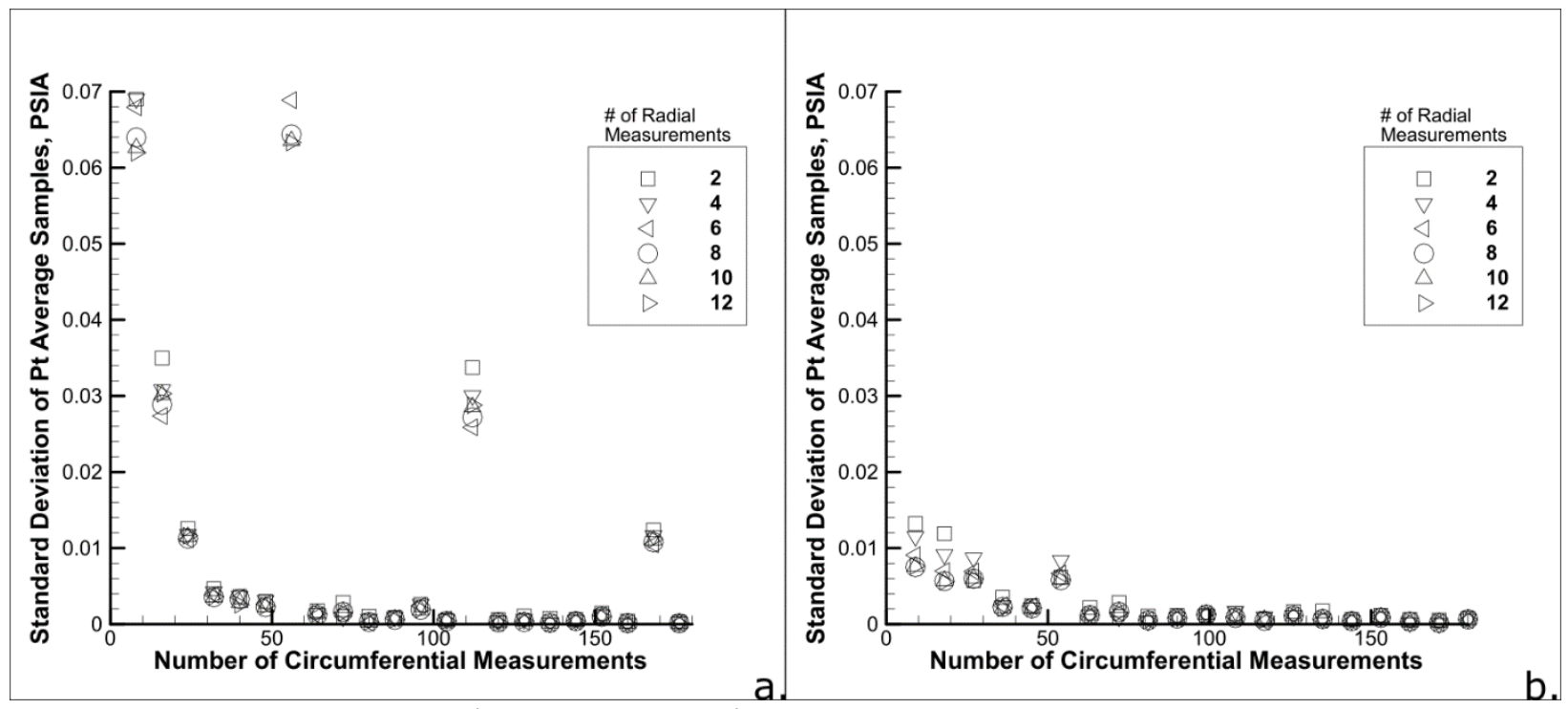

Figure 12. Total Pressure Deviations, a) 8-Rake FERRA and b) 9-Rake FERRA 

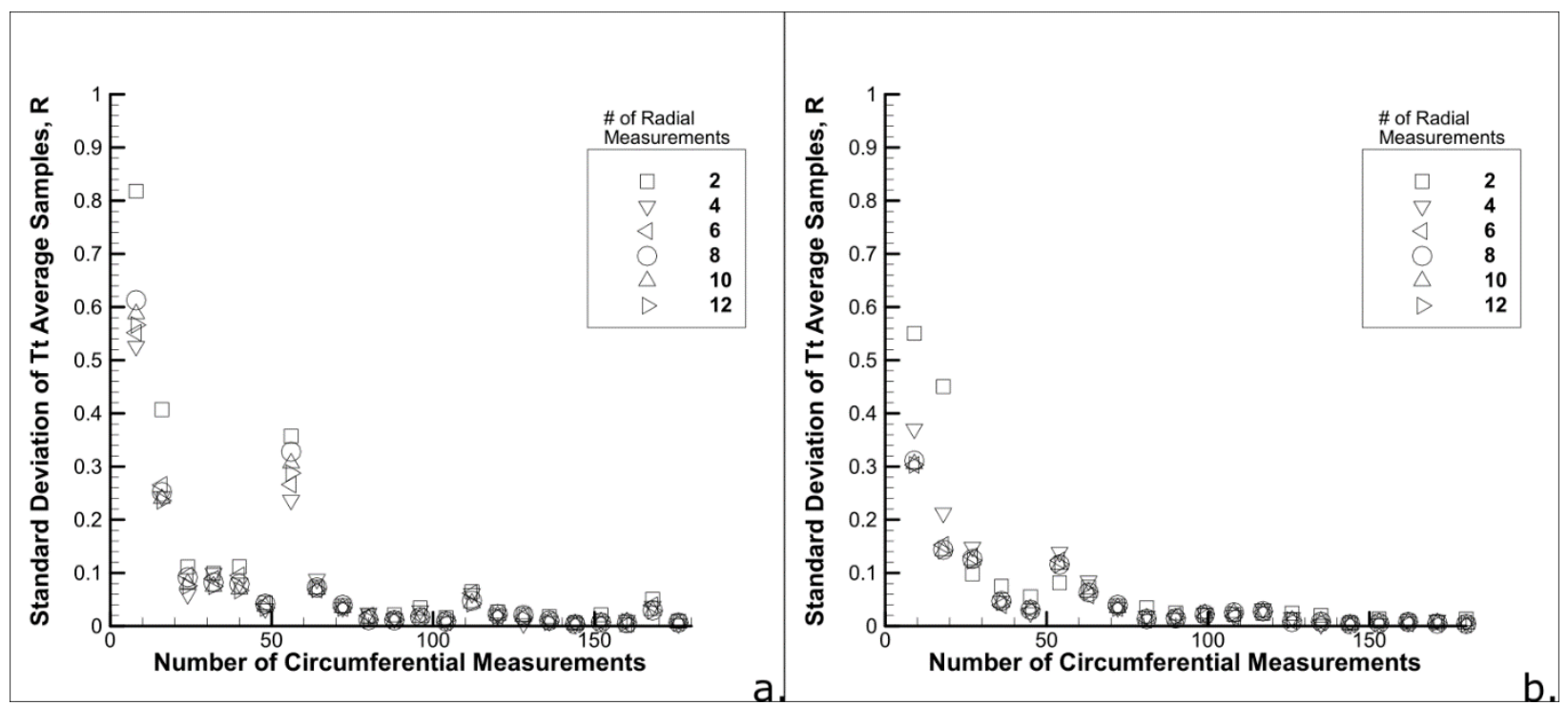

Figure 13. Total Temperature Deviations, a) 8-Rake FERRA and b) 9-Rake FERRA

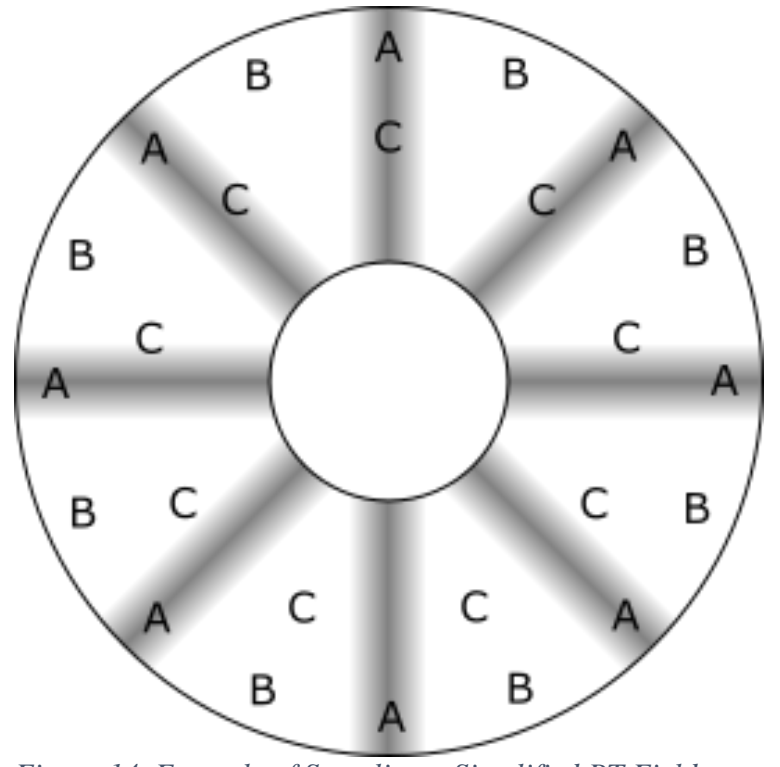

Figure 14. Example of Sampling a Simplified PT Field 


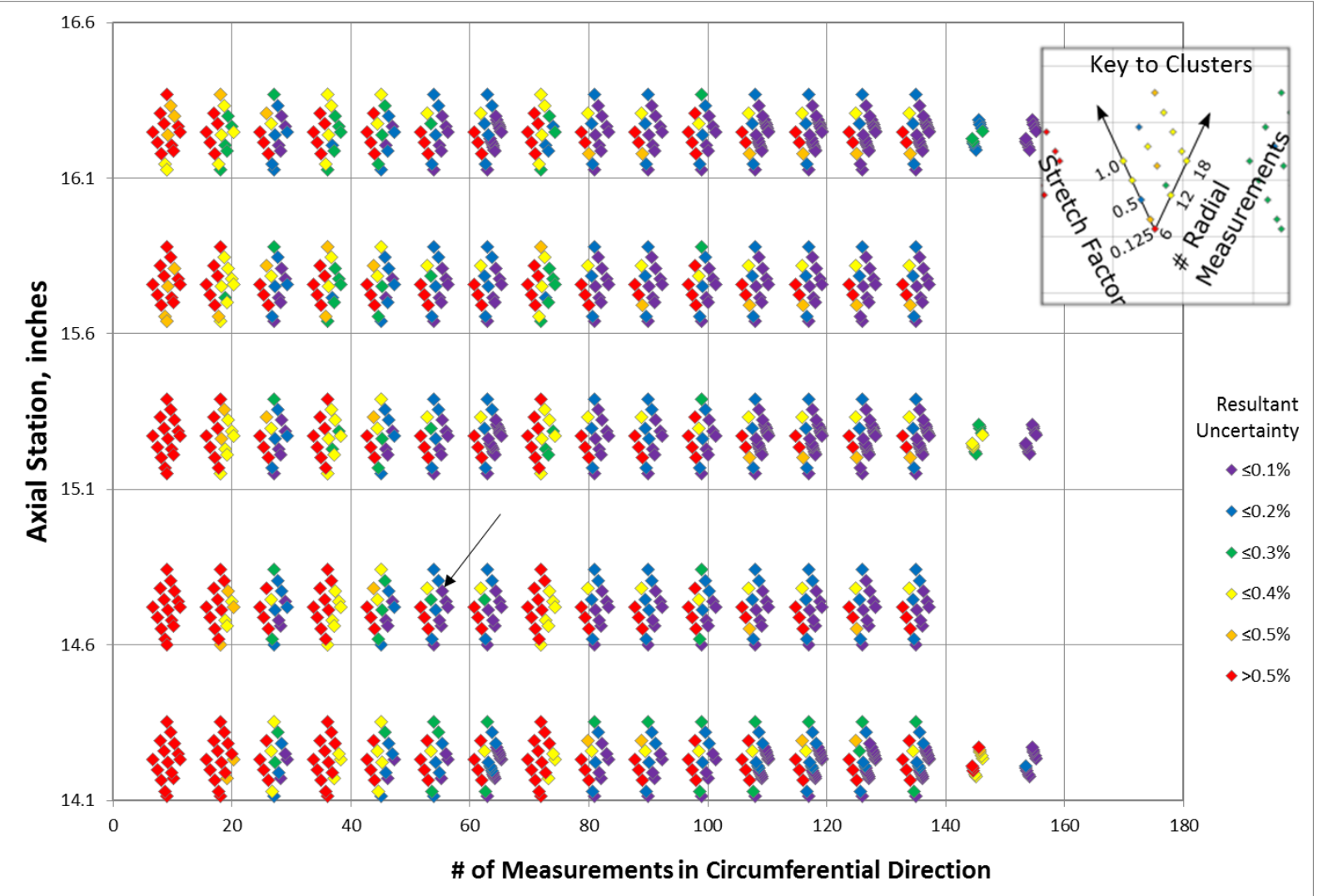

Figure 15. Effects of Multiple Variables on Standard Deviation of Mass Flow. Arrow shows minimum recommended conditions.

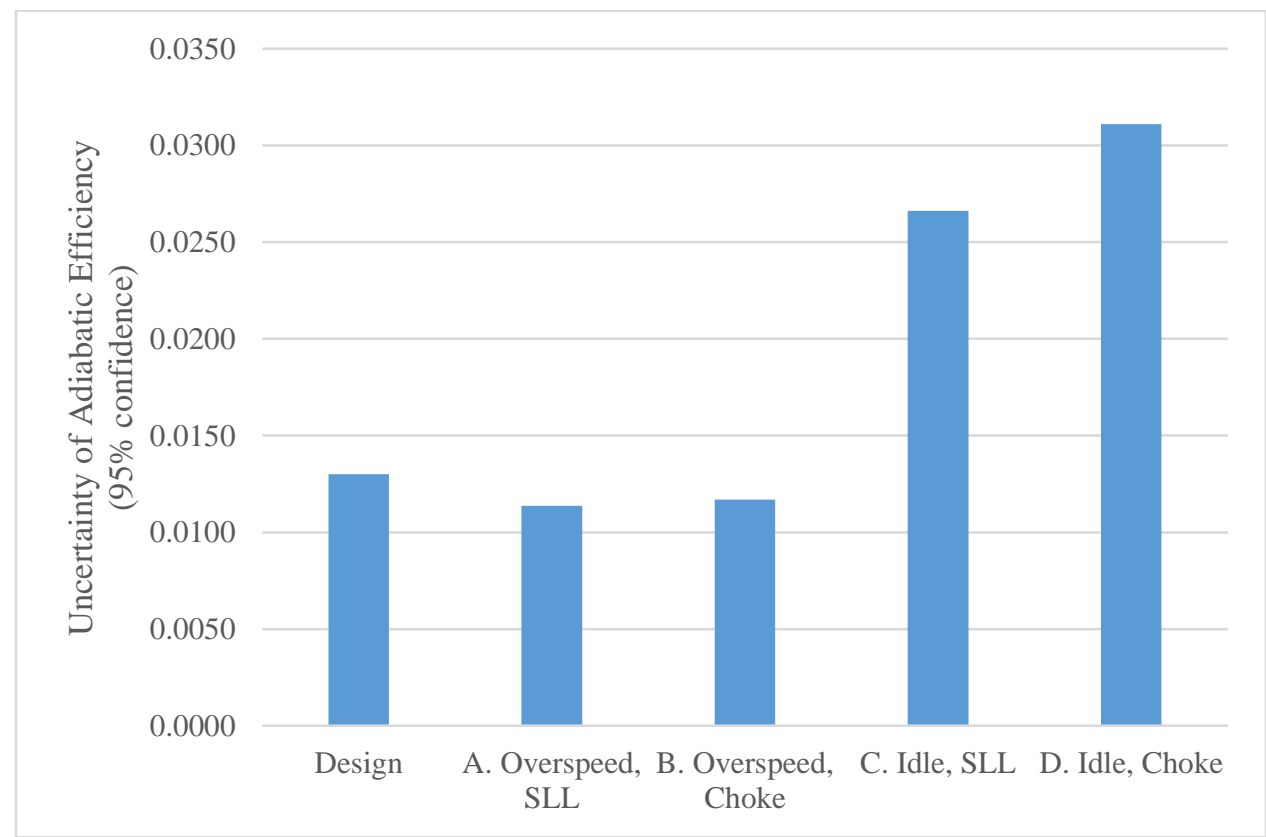

Figure 16. Pre-Test Uncertainty Estimates for Adiabatic Efficiency 


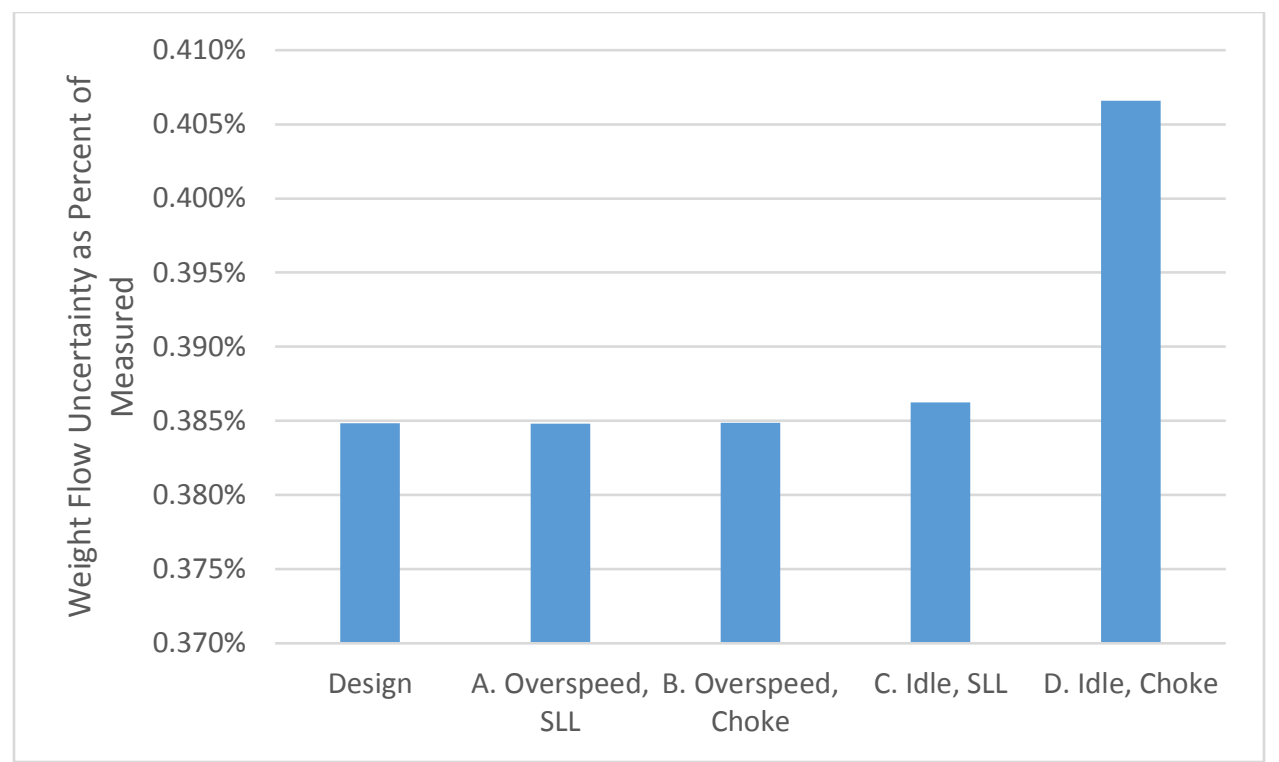

Figure 17. Pre-Test Uncertainty Estimates for Mass Flow Rate

a)

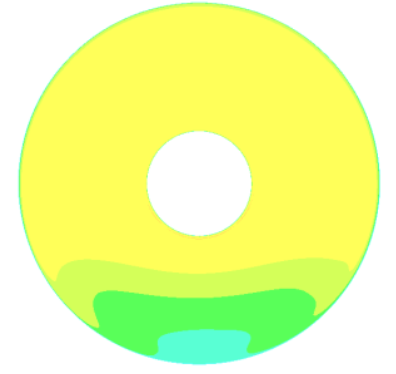

b)

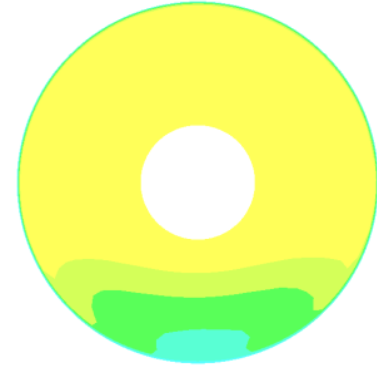

c)

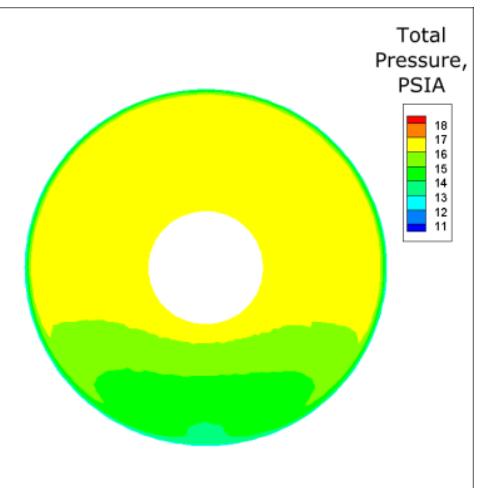

Figure 18. Comparison of Total Pressures at the AIPRRA. a) CFD Prediction, b) CFD Prediction Interpolated to Experiment Probe Positions, c) Experiment

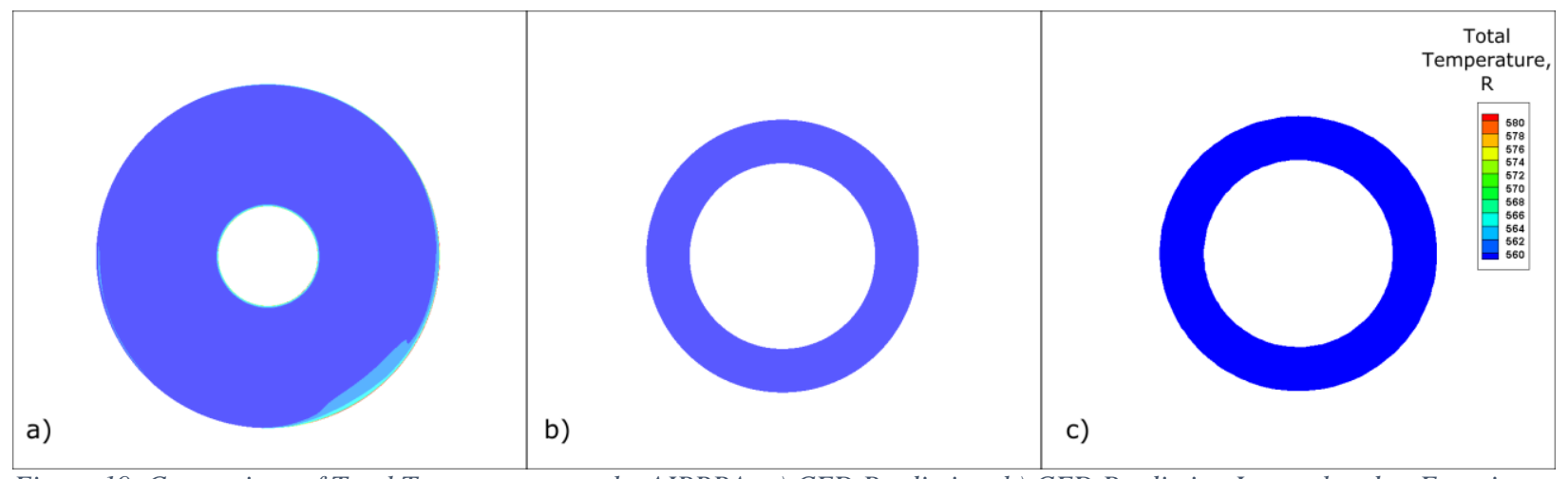

Figure 19. Comparison of Total Temperatures at the AIPRRA. a) CFD Prediction, b) CFD Prediction Interpolated to Experiment Probe Positions, c) Experiment 


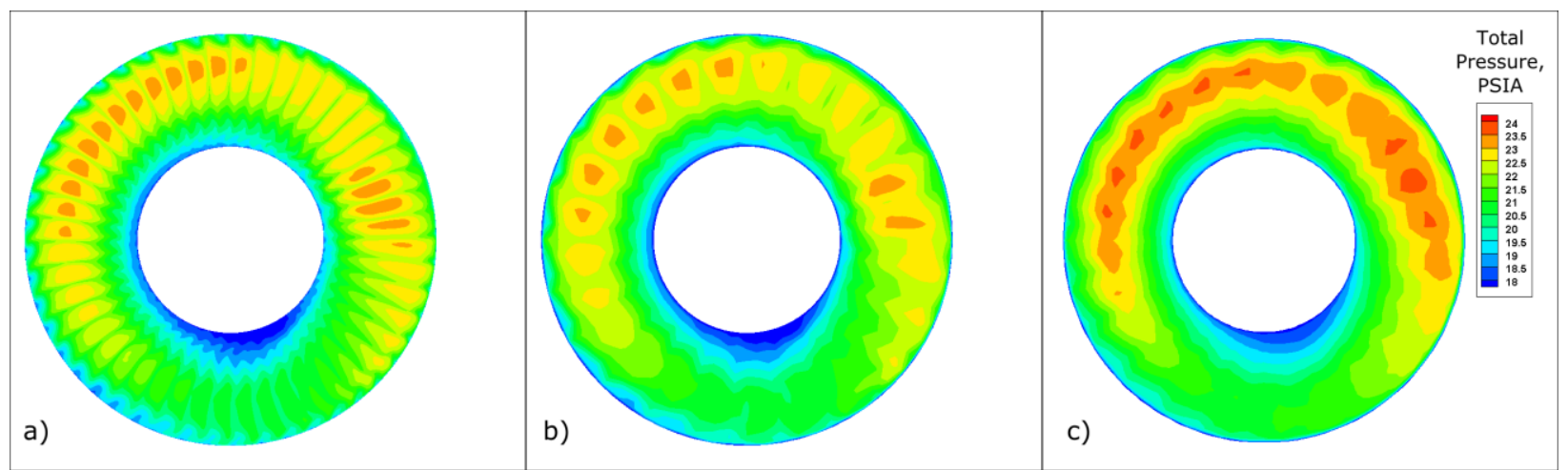

Figure 20. Comparison of Total Pressures at the FERRA. a) CFD Prediction, b) CFD Prediction Interpolated to Experiment Probe Positions, c) Experiment

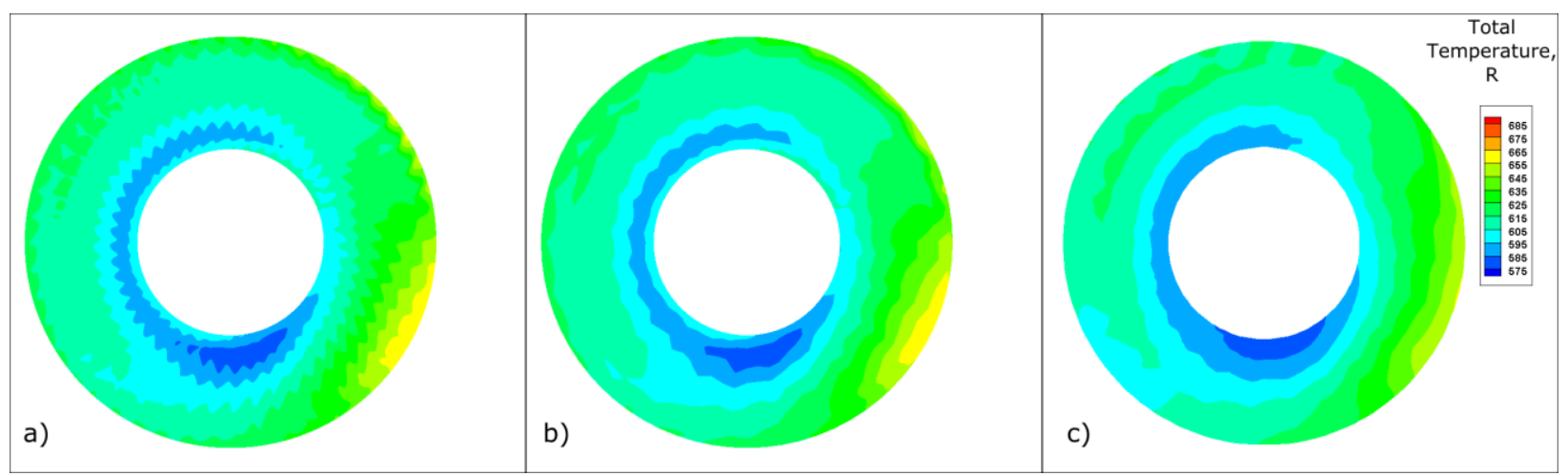

Figure 21. Comparison of Total Temperatures at the FERRA. a) CFD Prediction, b) CFD Prediction Interpolated to Experiment Probe Positions, c) Experiment 